\title{
Toledo frente a Madrid en la conformación del español moderno: el sistema pronominal átono*
}

\author{
Toledo against Madrid in the conformation of the modern Spanish: \\ the pronominal unaccented system
}

\author{
Pedro Sánchez-Prieto Borja \\ Universidad de Alcalá \\ pedro.sanchezp@uah.es \\ ORCID iD: https://orcid.org/0000-0001-7264-3986 \\ Delfina Vázquez Balonga \\ Universidad de Alcalá \\ delfina.vazquez@uah.es \\ ORCID iD: https://orcid.org/0000-0002-7842-7640
}

RESUMEN: Los estudios sobre el pronombre átono objeto en español señalan de manera casi unánime en las últimas décadas que el factor más importante para la selección de las formas $l e(s) / l o(s)$ para complemento directo es el tipo semántico del sustantivo de referencia (contable o incontable). Dentro de este sistema llamado referencial, se incluyen hoy las provincias de Madrid y Toledo. En este artículo examinamos los datos basados en documentos archivísticos inéditos de ambas provincias para 1) establecer si este sistema estaba vigente en la Edad Media, 2) señalar la extensión a partir del siglo XVI, 3) comprobar si el sistema leísta se extendía a todos los sociolectos y 4) precisar las diferencias geográficas internas del castellano central.

Palabras clave: pronombre, leísmo, Madrid, Toledo, documentos archivísticos, castellano central, variación.

ABSTRACT: In recent decades nearly all the studies about Spanish unstressed object pronouns state that the most important pattern for the choice of $l e(s) / l o(s)$ forms with

* Este estudio se ha llevado a cabo dentro de los proyectos "Corpus de Documentos Españoles Anteriores a 1800 (CODEA+ 2015)", financiado por el Ministerio de Economía y Competitividad (FFI2012-33646), y "Atlas Lingüístico Diacrónico e Interactivo de la Comunidad de Madrid (ALDICAM-CM)", financiado por la Comunidad de Madrid (S2015 HUM 3443).

Copyright: (C) 2018 CSIC. Este es un artículo de acceso abierto distribuido bajo los términos de la licencia de uso y distribución Creative Commons Reconocimiento 4.0 Internacional (CC BY 4.0). 
direct object function is the semantic kind (countable or uncountable) of reference noun. Nowadays Madrid and Toledo territories are included within this so-called "reference" system. The aim of this paper is to compare data based on unpublished archive documents from both Madrid and Toledo provinces in order to: 1) determine whether this system was in use in the Middle Ages; 2) establish its contextual use since the 16th century; 3) check if the le-system spread to all social dialects, and 4) describe in detail internal geographic variation in central Castilian.

Keywords: pronoun, leísmo, Madrid, Toledo, archival documents, central Castilian, variation.

En este artículo presentamos algunos de los resultados recientes del examen de la documentación de Madrid y Toledo, dentro de un proyecto integral de lingüística de corpus llevado a cabo por el Grupo de Investigación de Textos para la Historia del Español (GITHE) de la Universidad de Alcalá. Hemos seleccionado un problema muy tratado en la bibliografía, el de la variación en los usos pronominales, porque la documentación archivística puede aportar precisiones sobre los aspectos cronológicos y geográficos que influyen en este proceso tan significativo en la evolución del español.

\section{TOLEDO FRENTE A MADRID EN LA HISTORIA DE LA LENGUA ESPAÑOLA}

\subsection{El prestigio de la lengua toledana}

Los tratadistas de los Ss. XVI y XVII ya pusieron de relieve la excelencia de la lengua toledana, a la cual consideraban modelo del buen hablar, sobre todo por su conservadurismo frente a las formas menos prestigiosas de otras regiones castellanohablantes. De esta opinión son Sículo, Palmireno, Delicado y otros (González Ollé, 1996). Por el contrario, de Madrid se ha destacado su papel en la difusión de fenómenos innovadores como la aspiración de la $f$-, el ensordecimiento de sibilantes y el leísmo (Bustos y Santiago, 2000). Sin embargo, las opiniones de los autores clásicos tienen, muchas de ellas, un carácter impresionista, y otras no han sido valoradas por la crítica en toda su complejidad ${ }^{1}$. Tan-

\footnotetext{
${ }^{1}$ Observaciones como la de Villalobos en su Tratado de las fiebres interpoladas de 1515 se han de interpretar en clave sociolingüística y registral, y aun idiolectal referida a sí mismo, y no tanto en el marco de una disputa localista de la que el propio Villalobos, hombre de grandes alcances intelectuales, estaría muy por encima: "castellano [...] y no será el de Toledo, aunque allí presumen que su habla es el dechado de Castilla, y tienen mucha ocasión de pensarlo así, por la gran nobleza de caballeros y damas que allí viven; mas deben considerar que en todas las naciones del mundo la habla del arte es la mejor de todas [...]. Esta disgresión he hecho aquí, aunque es fuera de propósito porque las damas de Toledo no nos tengan de aquí adelante por zafios".
} 
to para la lengua de Toledo como para la de Madrid, se ha recurrido en pocas ocasiones a fuentes documentales ${ }^{2}$, hecho que resulta llamativo, especialmente en el caso de la ciudad del Tajo, pues sus archivos guardan una ingente documentación desde el s. XII (Sánchez-Prieto Borja, 2015).

\subsection{El relevo de Madrid}

Con el traslado de la corte a Madrid en 1561, la villa se convierte en nuevo foco de prestigio del español moderno, y este valor normativo se funda en 1) la afluencia de personas de la nobleza a la corte, 2) el desarrollo de la imprenta y, lo que no es menos importante, 3) la extensión de la escritura y su enseñanza reglada por medio de las cartillas impresas (Infantes, 1998). Todo ello no implica una uniformidad lingüística, debido sobre todo a la llegada en oleadas sucesivas de gentes de diversa condición social y de todas las regiones de España e incluso extranjeros. Como señaló Juan Jerez en 1620, "por esta conveniencia acuden a esta villa con igualdad los de Sevilla, Granada, Valencia, Cartagena, Pamplona, Vilvao, Santander, La Coruña y Lisboa (...)" (Jerez [c. 1601-1621], Razón de corte, CORDE). Un dato significativo es que Madrid pasó de tener 10.000 habitantes en 1530 a 90.000 en 1591 (López García, 1998). Frente a lo que suele decirse, no es seguro que el grueso de los que acuden a Madrid proceda de Valladolid, pues esta ciudad no pierde apenas población en el s. XVI; según el mismo autor, se mantiene cerca de los 38.000 habitantes que tendría a principios de siglo.

En consecuencia, Madrid debió de ser un espacio vivo de amplia variación sociolingüística. El problema radica en documentar los sociolectos más bajos, que, por otra parte, serían mayoritarios. La documentación producida por personas débilmente alfabetizadas y que solamente escriben en circunstancias excepcionales, aporta una muestra, siquiera mínima, de esta variación. Este es el caso de las notas de abandono de niños expósitos que llegan a la Inclusa de Madrid entre finales del s. XVI y principios del XVII. En ellas se transparenta fuertemente la oralidad, como se ve en muchas notas conservadas en el Archivo Regional de la Comunidad de Madrid (ARCM) ${ }^{3}$.

\footnotetext{
${ }^{2}$ Entre las excepciones, cabe citar a Matute Martínez (2004), que basa una parte de sus deducciones en los documentos incluidos en el corpus CODEA. Por otra parte, Echenique Elizondo (1981) considera los Documentos Lingüísticos de España. Reino de Castilla (edición de Ramón Menéndez Pidal, anejo LXXXIV de la RFE, Madrid, CSIC, 1966).

3 "La grande necesidad que una probe muger tiene obliga y fuerça acer esto. Por amor de Dios, vuestras mercedes le faborescan"; "Esta curiatura es de padres onrado, y ba con agua de la comadre por nacer con peligro"; "Agua lleba y Antonia se llama. Llevalda a la iglesia, crialda, y aceros á Dios bien” (Sánchez-Prieto Borja y Flores Ramírez, 2004).
} 


\section{FUENTES DOCUMENTALES PARA UNA NUEVA PERSPECTIVA DE LA HISTORIA} DEL ESPAÑOL: TOLEDO Y MADRID

Para este estudio hemos utilizado documentos procedentes del corpus $\mathrm{CO}$ $D E A$ en su versión de 2015, y los nuevos corpus de Madrid (ALDICAM) y Toledo (TOLEDOC), que abarcan desde los orígenes al s. XIX ${ }^{4}$. Por la cuestión estudiada, hemos seleccionado documentos de los ss. XVI y XVII de manera común, y en el caso particular de Toledo incluimos también la Edad Media, mientras que como testimonio madrileño para el s. XIII solo hemos considerado el Fuero de Madrid, pero no el de Alcalá5. Hemos descartado los textos emitidos por la cancillería real, pues estos son menos sensibles a las peculiaridades lingüísticas locales que la documentación eclesiástica, municipal y particular.

El examen directo de la documentación en los archivos, la selección de las piezas, su transcripción y estudio ha sido el procedimiento seguido para todos los testimonios y, en fase anterior, para los que proceden del CODEA. La dificultad de lectura de muchos manuscritos, en letra procesal algunos, ha condicionado negativamente el volumen del corpus. Era este, sin embargo, el único método que nos satisfacía, y ello nos ha llevado a no considerar transcripciones ajenas al grupo GITHE ${ }^{6}$. Tal exigencia no nace solo de la necesidad de contar con lecturas fiables, algo especialmente importante para diferenciar entre $l e / s$ y $l o / s$, sino de las posibilidades de conocer el proceso de elaboración del documento, las personas que intervienen en él, el grado de vinculación a la localidad de emisión, y aun su situación sociocultural. Somos conscientes de que las conclusiones son provisionales y que deberán afianzarse con nuevas fuentes documentales de las zonas examinadas. Fiamos nuestras interpretaciones no tanto a la cantidad de datos como al rigor de las ediciones y la representatividad de los materiales.

\footnotetext{
${ }^{4}$ En el caso de TOLEDOC $(<\mathrm{http}: / /$ www.textoshispanicos.es/index.php?title = Toledo_en_sus documentos $>$ ) solo se incluirán piezas de hasta el XVIII. La documentación madrileña se integra en un corpus que se configura como un Atlas Lingüístico Diacrónico e Interactivo de la Comunidad de Madrid, al poderse proyectar directamente en un mapa de la Comunidad de Madrid los resultados de las búsquedas, pues todos los documentos están localizados en el lugar de emisión.

${ }^{5}$ El original del Fuero de Alcalá, otorgado por el arzobispo de Toledo Rodrigo Jiménez de Rada, muerto en 1247, tal vez fue elaborado en el escritorio episcopal, y no en Alcalá de Henares, por lo que no puede considerarse testimonio del habla de Madrid.

${ }^{6}$ Para el Fuero de Madrid contamos con un excelente facsímil (Lapesa et al. 1994 [1932]) y para el de Alcalá, la edición de Torrens Álvarez (2002), cuyos criterios de transcripción compartimos.
} 


\section{EL PRONOMBRE ÁTONO OBJETO EN LA DIALECTOLOGÍA HISTÓRICA}

\subsection{Sistemas pronominales y variación geográfica}

Los estudios de dialectología hispánica señalan la actual provincia de Toledo como el límite actual del leísmo (Fernández-Ordóñez, 2001), de manera que gran parte de Ciudad Real y la totalidad de Andalucía siguen el sistema etimológico. La excepción al uso de leísmo en la zona de la provincia de Ciudad Real de los llamados Montes de Toledo se debe a la pertenencia histórica de este espacio al ayuntamiento de la ciudad de Toledo (Sánchez Sierra, 2014).

Los estudios de Klein-Andreu (2000: 95) señalan una diferencia para la sincronía actual entre el norte de Toledo, con un sistema innovador parecido al de Madrid, y el sureste, más cercano al sistema mayoritariamente etimológico de Ciudad Real. Además, en el sur los casos de leísmo obedecen al factor animación, mientras que en el norte la motivación de este fenómeno radica en referirse el pronombre a entidad masculina y contable. También el laísmo es mucho más frecuente en localidades del norte que del sur de la provincia ${ }^{7}$. Sin embargo, ambas zonas de la actual provincia de Toledo coinciden, según esta autora, en el rechazo a les para objeto masculino plural, en lo que se observa una diferencia significativa con los ámbitos más propiamente innovadores, como Valladolid, donde el leísmo plural es tan frecuente o más que el singular (2000: 100-101) ${ }^{8}$.

Fernández-Ordóñez (1999 y 2001) señala, a partir de los datos del COSER, que en el occidente de Toledo se distingue, para el objeto, entre los masculinos contables (le) y no contables (lo), y lo mismo en las zonas referenciales de Cáceres y Ciudad Real.

En la comarca de la Jara, que incluye el suroeste de Toledo, sureste de Cáceres y noroeste de Ciudad Real, se aprecian, según Paredes García (1995: 348), usos basados, al parecer, en el género": "Están totalmente extendidos por la comarca los fenómenos sintácticos conocidos como laísmo, leísmo y loísmo. La relación que se establece entre el nombre y el pronombre tiene que ver casi exclusivamente con la concordancia, sin que se influya la función que desempeñan. De esta forma se tiende a usar siempre la para el femenino y le/lo para el masculino: "el río hay que

\footnotetext{
${ }^{7}$ En el sur le para objeto indirecto femenino llega al 97\%, mientras que en el norte KleinAndreu (2000: 60) registra un $22 \%$ en el grupo de población con menos contacto con otras variedades, $56 \%$ en el que más, y $59 \%$ en el intermedio.

${ }^{8}$ La causa de esta generalización del leísmo en Valladolid para el plural hay que buscarla en la intervención del carácter contable o no contable, pues mientras que en singular los objetos no contables se referencian con $l o$, al no estar operativa esta distinción en el plural, el pronombre es prácticamente siempre les.

${ }^{9}$ Las poblaciones toledanas incluidas en los ejemplos son: Navalmoralejo (q), Espinoso (m), Puerto (u), San Bartolomé (x) y Sevilleja (y).
} 
cruzarle" (iH4A), "al niño lo pusieron unos pantalones" (qM3A), "el queso hay que partirle" (mH1B), "al botijo le colgamos" (uM4A), "a la madre no la dieron nada" (xH2A), "los da miedo" (yM4A), "lo echan azúcar" (çM4A), "se los cae encima" (çM4A), "a la yegua la cansa el trabajo" (aH4A), "a las niñas no las gusta estudiar” (gH4A)'. Sin embargo, como señala Fernández-Ordóñez (1999 y 2001), el loísmo para persona singular solo de forma anecdótica se documenta en el COSER y en el ALPI, y se emplea de manera prácticamente exclusiva para entidades no contables en singular y contables masculinas en plural.

En cuanto a Madrid, se ha de señalar, según los datos del COSER, que en el área occidental de la provincia no hay leísmo de plural para referentes animados (Fernández-Ordóñez, 2001), mientras que en la oriental el leísmo se extiende al plural (Paredes García, 2015: 183). En la zona occidental de Madrid y Toledo se da, pues, un sistema referencial con le/los, mientras que el este y sur de Madrid y el oriente de Toledo muestran un mayor peso del carácter animado en la selección de le para el pronombre objeto, y conocen un empleo esporádico del laísmo (Fernández-Ordóñez, 1994).

\subsection{Causa histórica de la variación geográfica}

Por otra parte, la justificación de los límites de los sistemas leístas se ha buscado en la Reconquista y Repoblación (Fernández-Ordóñez, 2001) ${ }^{10}$. Queda, sin embargo, por resolver la cuestión de por qué se frenó la expansión del sistema leísta referencial en Ciudad Real y Andalucía, siendo zonas con repoblación mayoritariamente castellana. Quizá pueda contribuir a entender mejor el mantenimiento del sistema etimológico el hecho de que en el ámbito registral y sociolingüístico representado por la documentación de la cancillería de Fernando III y Alfonso $\mathrm{X}$ se mantuviera, aunque no sin excepciones, el sistema etimológico (Almeida, Sánchez-Prieto y Vázquez, 2015; Martín Aizpuru, 2015). El examen inicial de diversos textos toledanos de CODEA y TOLEDOC puso de relieve la existencia de un sistema referencial prevalente en Toledo en los ss. XVI y XVII, cuya manifestación es el leísmo de entidades animadas y objetos contables masculinos singulares ${ }^{11}$.

${ }^{10} \mathrm{El}$ desconocimiento de las proporciones entre los lugares de procedencia de los pobladores que se establecieron en Toledo (González, 1987) dificulta valorar la filiación lingüística de los usos medievales, por lo que la idea de una "koinetización" de los usos de diferentes lugares y de los mozárabes toledanos (Tuten, 2003) resulta conjetural, y solo podrán alcanzarse precisiones tras el examen de la documentación. Por otra parte, la repoblación del antiguo reino de Toledo no puede considerarse cumplida de manera inmediata tras la reconquista de 1085, sino que constituyó un proceso prolongado en el tiempo.

${ }^{11}$ Con todo, pueden aducirse dos testimonios etimológicos tardíos en cartas de emigrados toledanos a México todavía en el s. XVI (Frago, 1999: 38 y nota 61). 
La finalidad del presente estudio no es, pues, discutir el origen último de las formas alternativas al sistema etimológico, sino poner el foco en el espacio central peninsular para intentar precisar la cronología, extensión social y geografía de la difusión de estas innovaciones leístas, laístas y loístas. Este proceso se podría entender mejor si el punto de partida fuera un sistema etimológico asentado mayoritariamente en la Edad Media tanto en Toledo como en Madrid.

\section{El Sistema PRONOMINAL Átono EN LAS FUENTES DOCUMENTALES DE MA- DRID Y TOLEDO EN LA EDAD MEDIA}

\subsection{Documentación medieval toledana}

En las piezas de los ss. XII y XIII de los archivos toledanos domina el sistema etimológico de manera prácticamente absoluta, y así se referencian con $l o$ tanto el objeto directo de persona singular ( 1 y 2 ) como el de entidad contable singular (3 y 4):

(1) E nós porque entendemos su buen propósito y honesto otorgámosles que fiziessen su casa sobre tal condición como de suso es dicho e que el clérigo que ý oviere de ser que lo pongamos nós que sea en nuestra obediencia (ACT A.3.B.1.4., Toledo 1239); (2) [...] estos son de villa y de aldeas que metieron al arçobispo don Rodrigo de mandado del concejo de Guadalfajara en Turviese con el término que desuso es dicho. Testigos delant quien lo metieron en la heredat de Turviese en aldea e en su término: don Pero Vidas, alcalde del rey don Fernando, Diag Díaz [...] (ACT O.2.Q.9.2., Toledo 1221).

(3) Alzastes maes de la medida. Vadant a la pesquera, e midan del solo inter amas las canales fata el petril que es el cabo de la pesquera, e si fallaren maes alzado de como está la medida en la torre desátenlo (ACT, Toledo 1199); (4) [...] e que la tengades [la viña] en todos vuestros días e que nos dedes de arrendamiento por ella cad'año I moravedí, e que nos lo dedes por carrastellendas (ACT O.8.G.1.57, Toledo 1258).

Más adelante, en el s. XIV, se observa en Toledo el uso predominante de formas etimológicas (5 y 6), aunque también se encuentran 2 casos de leísmo de persona (7 y 8). La variación se aprecia en el mismo documento (5, 6 y 7):

(5) E el dicho Toribio Fernández embióme pedir merced que lo amparase e defendiese con el dicho prioradgo, e yo tóvelo por bien (CODEA 200, 1354); (6) [Toribio Fernández] recebímoslo e estatuémoslo en prior del dicho prioradgo e de todos sus derechos e pertenencias e envestímoslo d'él por nuestro aniello (CODEA 140, Toledo 1353).

(7) el dicho Toribio Ferrández por que sea prior de la dicha eglesia de Santa María, e rogámosvos que $l$ recibades e $l e$ instituyades en prior e administrador de la dicha eglesia (CODEA 140, Toledo 1353); (8) que vos mando vista 
esta mi carta que amparedes e defendades al dicho Toribio Ferrández con el dicho prioradgo e le ayudedes en todas las cosas que aya mester vuestra ayuda (CODEA 200, Toledo 1354).

Las Ordenanzas de Toledo de 1400, editadas por Tello Martín (2006), tampoco muestran un sistema referencial, pues los objetos contables animados, como novillo bravo, se recuperan con lo:

(9) Otrossí ningund carnicero que no compre novillo bravo en Toledo nin en su término para lo matar [...]. E otrosí si comprare novillo bravo fuera del término e algund vezino de Toledo lo quisiere para arar que lo pueda tomar (Ley VII $)^{12}$; (10) Pero cualquier vezino de Toledo e morador que quisiere vender su buey, tájelo en la carnecería e puédalo vender como quisiere [...] (Ley VIII).

Es decir, el pronombre es el mismo que en los incontables como vino:

(11) E que non metan en Toledo el vino que d'ellos ovieren nin lo vendan a otro alguno que lo meta en Toledo. [...] E que el registrador que non registre a estos que dichos son su vino nin le den alvalaes para lo meter sabiéndolo [...] e la valía del vino que registró o dio alvalaes para lo meter [...] (Título V).

Todavía a mediados del s. XV (1456) encontramos usos etimológicos para persona (12), y aun a finales de siglo, en un documento de 1489 emitido en Mazarambroz, al sur de la ciudad de Toledo (13), aunque en el mismo y en otro datado en 1434 en Maqueda (norte de la provincia), se cuenten dos casos más de posible leísmo personal (14 y 15):

(12) e prendieron al dicho mi moço e lleváronlo [...] onde juró en el dicho logar lo avían tomado que non eran descaminadas las dichas bestias e trigo ([Toledo] 20 de febrero de 1456).

(13) dize que está a pie, y así me lo embió a dezir Solano desde Galve, que le avían hurtado la mula, que no se deve consentir qu'él aya d'estar ni venir a pie, pues no creo yo que ninguno de la merced de vosotros si allí lo oviese embiado [...] (AMTO 1474, Carta de Gómez al ayuntamiento de Toledo, Mazarambroz, 1489).

(14) que aun yo por averle [a Solano] nombrado seré contento de ayudarle [a Solano] de lo mío ${ }^{13}$ (AMTO 1474, Carta de Gómez al ayuntamiento de Toledo, Mazarambroz, 1489).

\footnotetext{
12 Notamos que res se referencia con lo, seguramente por cruce con el referente novillo que aparece inmediatamente antes y se hace explícito al final: "E si otra res biva comprare en la villa o en el término, si el vezino morador en Toledo o en su tierra lo quisiere ante qu'el precio aya pagado el carnicero, e jurando el vezino que lo quiere para sí e para su labrança e que non para vender, que lo pueda aver pagando luego el precio por que assí compró el carnicero el dicho novillo" (Ley VII).

13 Los ejemplos medievales de CORDE de lo ayudar apuntan tal vez a un proceso de transivitización temprano. Parece, pues, que hubo variación antigua entre le y lo con este verbo.
} 
(15) al dicho señor condestable, e le dedes e entreguedes a él o al que su poder oviere la tenencia e posesión d'esas dichas villas e lugares, aviéndole por señor e faziéndole la reverencia (AHN Nobleza, Condes de Baena, 32, D. 12 Maqueda (Toledo), 16 de junio 1434).

Aunque hay algunos casos de leísmo de persona masculino singular, predomina el uso etimológico en el plural durante el s. XV (16) ${ }^{14}$. Por otra parte, en el mismo documento citado de 1456 hay una muestra del pronombre lo para entidad contable o contable abstracta ${ }^{15}(17)$. Además, encontramos un nombre no contable femenino referenciado con el pronombre $l o$, que se podría interpretar como neutro de materia, por tratarse de una entidad continua, la greda, un tipo de arcilla (18):

(16) e pues que los dichos reos no parecían a oír sentencia él los avía e ovo por rebeldes (AHN Nobleza, Condes de Baena, 224, D. 101-102 Toledo, 12 de abril de 1464).

(17) no era obligado de pagar el dicho portadgo por ser vezino e morador d'esta dicha cibdad nin por lo traer para vezino e morador d'ella nin avía de qué a pagar lo oviese ([Toledo] 20 de febrero de 1456).

(18) ca de otra guisa a mí se recrecería muy grand daño e seríame necesario de non dar la dicha greda a los dichos perailes salvo a los precios que lo vendo para fuera d'esta cibdad (AHN Nobleza, Condes de Baena, C. 173, D.110, Toledo 1456, 2r).

Para completar la descripción de los usos pronominales toledanos se han de considerar los casos de apócope. Esta es general en los contextos sintácticos apropiados (Almeida, Sánchez-Prieto y Vázquez 2015: 591), pero solo afecta a los objetos indirectos, con dos excepciones:

(19) E por esta orta que sea tenudo el arzobispo don Rodrig e los otros arzobispos que después d'él serán de fazer mio aniversario cad'año en su casa después de mi fin. E todo esto que es conombrado en esta carta dógelo, e esco $\cdot \mathrm{m}$ d'ello de oy adelant, e apodero $l$ e meto $l$ en ello (San Audito, Toledo, 1221).

No es, pues, seguro que estos casos sean interpretables como leísmo, pues la apócope del pronombre objeto puede darse en documentos de sistema etimológico (CODEA 155, San Salvador de Oña, 1229): (20) "Otrossí dixo del molino que $l$ ganó ell abade don Martino [...]. El molino ganólo ell abade don Martino"16.

\footnotetext{
${ }^{14}$ No obstante, en el Corbacho, del toledano Alfonso Martínez, el pronombre le alcanza el 80\% para objeto directo personal (Lapesa, 2000: 291).

${ }^{15}$ Referentes considerados de "ente contable", en género masculino y número singular, con un sentido "concreto" son sustantivos como libro, documento o jarrón. En cambio, contable abstracto sería el caso de pleito, salario, poder, aunque este último puede referirse a 'documento de poder' (concreto) y 'autorización' (abstracto), como en la expresión dar poder.

${ }^{16}$ Encontramos casos de apócope para objeto directo masculino singular; puesto que este sistema de la documentación toledana es etimológico, concluimos que solo se apocopa le. Natural-
} 


\subsection{Documentación medieval madrileña}

Aun con las dificultades inherentes a la adscripción geográfica de testimonios de tanta antigüedad, para la lengua de Madrid cabe contar el Fuero de esta villa, al parecer elaborado por el concejo ad honorem del rey Alfonso VIII entre 1158 y 1202 (Lapesa et al. 1994 [1932]: 16), y que presenta siempre usos etimológicos. Con referente persona contamos, entre otros, los siguientes:

(21) Ad cui habuerit suspecta de morte de omne que lo firio et per ipsas feridas murio (VIII); (22) Todo omne qui exierit per enemico de Madrid, el vecino de Madrid o de suo termino qui lo acogiere in sua casa pectet $\mathrm{X}$ morabetinos (IX); (23) Todo omne de Madrid que intrare con forza [...] et ibi matare el senor de la casa aut dona de la casa vel filio de la casa aut alguno de suos parentes [...] et iuret el senior de la casa aut dona de la casa quod achel homine que dice, esse lo mató vel firió (XIV); (24) Toto homine qui desornare ad hospite de suo vezino, nisi dixerit primo [...] et si antes lo desornare (XXI).

Con referente de entidad contable abstracta (25) y con referente neutro (26) el pronombre siempre es $l o$ :

(25) Et el vicino que fuerit con el aportelado ad acotar et no lo quisiere otrogar, iure quod no lo hodió el acotamiento que el jurado con ille fizo (IX).

(26) Todo omne qui arancada hoviere por iudicio de alcaldes ad suo contendor et despues gelo negare, pectet II morabetinos (XXXV).

El único caso de leísmo para persona masculina singular es CVIII: (27) "Todo homine qui firiere vezino a vezino [...] firmet cum II testemunas [...] e si no le firmaren, sálvese con II vicinos", donde firmar es un tecnicismo jurídico que, aunque normalmente ha de interpretarse como 'probar', aquí puede significar 'avalar (a alguien en) lo que dice'. Quizá haya de sumarse a los usos no etimológicos el empleo de los para objeto indirecto en (28) "per la calomnia que arrancaren per iudicio vel per carta los fiadores non solten de illo nada, e si antes los rogaren solten", aunque no con seguridad debido a la variación en el régimen de rogar. Los tipos más representativos se cuentan en esta tabla

mente, esto no quiere decir que en textos de otras zonas no sea posible la apócope de lo (así, en la Biblia Esc. I.I.6, de sistema etimológico mayoritario, hay apócope tanto para objeto directo como indirecto). Matute Martínez (2004: 271, 305) presenta mapas de apócope de OD y leísmo en documentos notariales locales; de apócope para complemento directo en p. 271, y de le para la misma función en p. 305. En las áreas donde hay leísmo (salvo en Liébana), también se da apócope (esto ocurre en León, Palencia y Ávila); la autora señala apócope de complemento directo sin leísmo en Navarra, Huesca, zonas de Zaragoza, norte de Cantabria y Burgos. 
(Figura 1), en la que los números de la izquierda de la barra corresponden a los usos leístas y los de la derecha a los etimológicos ${ }^{17}$ :

\begin{tabular}{|l|c|}
\hline Leísmo de persona masc. singular & $1 / 23$ \\
\hline Leísmo de persona masc. plural & $0 / 2$ \\
\hline Leísmo de animal masc. singular & $0 / 2$ \\
\hline${\text { Leísmo de entidad contable singular }{ }^{18}}^{18}$ & $0 / 3$ \\
\hline${\text { Leísmo de entidad contable plural }{ }^{19}}$ Leísmo de entidad incontable singular & $0 / 2$ \\
\hline Leísmo de entidad contable/abstracta singular & $0 / 3$ \\
\hline Leísmo de referente neutro & $0 / 2$ \\
\hline
\end{tabular}

FiguRA 1.-Leísmo/uso etimológico en el Fuero de Madrid

Aun con las dudas expresadas sobre su adscripción geográfica, añadiremos que en el Fuero de Alcalá se documenta un caso de leísmo para persona (Torrens Álvarez, 2002: 287): (29) 260, 46v "Todo omne qui casa toviere poblada in villa e pendrárenle in aldea ad él o a sos omnes", pero lo es general con el verbo pendrar, como en (30) 251, 46r "Todo omne qui ad otro toviere pendrado e el otro lo pendrare". En el plural se atestigua un caso de leísmo con un verbo que selecciona objeto directo personal, juzgar: (31) 134, 24v, "Et si alguno bezino d'Alcalá o de so término diere rencura al iudez por coto o a fiadores por algunas cosas, si no les fizieren aver derecho no les judguen los alcaldes hata que ayan derecho los rencurosos". No obstante, salvo estos casos contados, domina el uso etimológico tanto en singular como plural en persona y entidad contable.

\section{EL USO DEL PRONOMBRE ÁTONO EN LA DOCUMENTACIÓN DE MADRID Y TOLEDO DE LOS SS. XVI Y XVII}

\subsection{Toledo}

Mientras que hasta el s. XV el leísmo de persona aparece de una manera minoritaria, la documentación muestra que en los dos siglos siguientes tiene

${ }^{17}$ El pronombre apocopado se encuentra en el Fuero de Madrid solo para objeto indirecto de persona $(28,8 \mathrm{r}$, e denegue los verbos que $\cdot$ l dixot).

${ }^{18}$ Las entidades referenciadas son carrascal, coramne 'pellejo' y garavato 'frenillo que se pone a los perros para que no muerdan', de las cuales tal vez la primera debiera excluirse de este grupo.

${ }_{19}$ Aunque la expresión "contable plural" es redundante, pues los plurales son contables, la hemos mantenido en las tablas por el paralelo con "contable singular". 
lugar un proceso de extensión del fenómeno, y así, en Toledo hay leísmo generalizado para persona masculina singular (32 y 33), y también para animal (34), por lo que el factor animación parece favorecer $l e$ :

(32) Nuestro Señor su magnífica persona guarde y le coloque como merece (AHN Diversos, Colecciones 15, $\mathrm{n}^{\circ}$ 1187, Toledo, 5 de marzo de 1548).

(33) Alonso Vaca de Herrera [...] nos obliga a suplicar a vuestra señoría ilustrísima nos la haga en favorecerle con su magestad por el memorial que diere (Archivo General de Simancas, Patronato Real, Legajo 79, documento 44, Toledo, 1582).

(34) Alonso Díaz, vezino de Yébenes, digo qu'el día de los toros en servicio de vuestra señoría yo tube un toro de los cuernos para derriballe en el suelo, y al tiempo que le tenía asido me dieron en una pierna con una garlocha (TOLEDOC 315, Toledo 1609).

A pesar del número reducido de casos, quizá puedan apuntarse algunas preferencias espacio-temporales de la selección del pronombre (Figura 2) ${ }^{20}$. En primer lugar, se confirma el avance del leísmo de persona ya en la segunda mitad del s. $\mathrm{XV}$, aunque con un mantenimiento casi igual de los usos etimológicos, como se vio en el documento de Mazarambroz de $1489^{21}$. En esta misma tabla, el leísmo de persona plural, representado únicamente por 3 casos ya del siglo XVII, parece tener una presencia tardía y marginal, por lo que podría encajar con la tendencia señalada en la sincronía actual a adoptar los para objeto en el plural tanto en el norte como en el sur de Toledo (Klein-Andreu, 2000:100-101). En el singular, con referente animal masculino se aprecian 4 casos en la primera mitad del s. XVII y 2 en la segunda del XVIII, mientras que para este referente no tenemos ninguna muestra de $l o$ :

\begin{tabular}{|l|c|c|c|c|c|c|c|c|}
\hline \multicolumn{1}{|c|}{ Tipo de alteración } & \multicolumn{2}{c|}{ s. XV } & \multicolumn{2}{c|}{ s. XVI } & \multicolumn{2}{c|}{ s. XVII } & \multicolumn{2}{c|}{ s. XVIII } \\
\hline Leísmo de persona singular & & $3 / 2$ & $2 / 0$ & $8 / 0$ & $5 / 0$ & $4 / 0$ & $1 / 0$ & $5 / 1$ \\
\hline Leísmo de persona plural & & $0 / 1$ & & & $1 / 1$ & $1 / 0$ & & $1 / 0$ \\
\hline Leísmo de animal singular & & & & & $4 / 0$ & & & $2 / 0$ \\
\hline Leísmo de animal plural & & & & & & & & $0 / 1$ \\
\hline
\end{tabular}

FIGURA 2.--Leísmo/uso etimológico con referente animado ${ }^{22}$ en Toledo en los ss. XV-XVIII

${ }^{20}$ Los datos se presentan por mitades de siglo, con los usos innovadores a la izquierda de la barra (/) y los etimológicos, a la derecha.

${ }^{21}$ Ya en el s. XVI, las actas capitulares de la catedral muestran un empleo absoluto del leísmo personal, al menos desde 1548: "lunes IX de julio de 1548 [...] Este día se presentó en cabildo un entredicho a pedimiento del promotor fiscal por la prisión de Bartolomé de Peña, teniente de pertiguero y los dichos señores le obedecieron y mandaron poner; a la plegaria tratóse el processo" (Actas capitulares, Tomo VIII, Toledo, 9 de julio de 1548).

${ }^{22}$ Aunque "animado" abarca tanto 'animal' como 'persona' y a efectos sintácticos ambos grupos tienen el mismo comportamiento, hemos contado separadamente referente persona y animal para dar una visión más detallada del proceso histórico de extensión del leísmo. 
Además, en el corpus se ven casos de leísmo de entidad contable masculina singular, como los siguientes:

(35) Pedro Gómez, como tal maestro de albañilería, de cercar el dicho maxuelo [...] y ha de roçarle a su costa, y dicho Joán de Avilés ha de traerlo por su cuenta a la obra y ha de quedar y dexarle cercado por tres partes (TOLEDOC 282, Toledo 1634).

Por otra parte, ante un referente plural se aprecia un caso de leísmo (36), pero todavía en el s. XVI dominan las formas etimológicas (37 y 38):

(36) pido y suplico a vuestra señoría se me libren los mil reales de la obra pía, mandando que luego me les pase el receptor (TOLEDOC 233, Toledo, 1607).

(37) Este día estando los dichos señores deán y cabildo capitularmente ayuntados mandaron que los libros de las congregaciones los guarde el racionero Alonso Sánchez y los recoxga todos (Actas capitulares, Tomo XII, Toledo, agosto, 1565); (38) ochenta y cuatro mil maravedís ofreció de pagárselos e volvérselos con mucha brebedad (Archivo de la Chancillería de Valladolid, Ejecutoria, Caja 1621, 72, Toledo 1588).

Aunque no es habitual, con referente contable abstracto se encuentran algunos casos de leísmo. Consideramos contable abstracto el sustantivo que muestra oposición uno/varios, pero cuyo componente semántico no es del todo concreto, como pleito, que aparece en el siguiente documento de 1588:

(39) que él deseava que se viese este pleito, mas que beía que por falta de juezes cada día avía dos salas de menor cuantía o se quedava una sala cerrada, que él me dava palabra que, en aviendo juezes, que le haría ver luego (TOLEDOC 199, Granada, pero emisor toledano, 1588).

Un caso particular es el uso de $l o$ para un posible neutro de materia ${ }^{23}$ con un sustantivo femenino, vaca, en el sentido de 'carne de vaca':

(40) y ansimismo los despoxos de las bacas que se mataren en esta ciudad contengo a mi cuenta y las tengo arrendadas, y ansimismo estoy obligado al acarreo de la vaca y ponerlo en las carnicerías d'esta ciudad (TOLEDOC 252, Toledo 1618).

Desde un punto de vista cuantitativo, destacamos los 6 empleos de le, por ninguno de $l o$, en la primera mitad del s. XVII. Con referente incontable masculino singular la pronominalización se hace siempre con lo en nuestro corpus. Llama la atención el progreso de le para entidad contable abstracta singular,

\footnotetext{
${ }^{23}$ Otra posibilidad sería considerar que el pronombre $l o$ tiene un referente neutro, con el sentido de 'todo ello'.
} 
pues si todavía en la segunda mitad del s. XVI encontramos 5 empleos de lo por solo 1 de $l e$, las proporciones se invierten en el s. XVIII, y así computamos 5 veces le frente a ningún caso de $l o$. En cambio, no hay casos de leísmo para referente neutro, ya que en las 27 apariciones de esta clase de referente siempre neutro se selecciona $l o$, del tipo (41) “[...] y está presto de hazer y cumplir $l o$ que se les manda por ella y para lo cumplir pide se le entregue esta real provissión".

\begin{tabular}{|l|c|c|c|c|c|c|c|c|}
\hline \multicolumn{1}{|c|}{ Tipo de alteración } & \multicolumn{2}{|c|}{ s. XV } & \multicolumn{2}{c|}{ S. XVI } & \multicolumn{2}{c|}{ S. XVII } & \multicolumn{2}{c|}{ S. XVIII } \\
\hline $\begin{array}{l}\text { Leísmo de entidad contable } \\
\text { singular }\end{array}$ & $1 / 0$ & & & $1 / 0$ & $6 / 0$ & $2 / 0$ & & \\
\hline $\begin{array}{l}\text { Leísmo de entidad incontable } \\
\text { masculino singular }\end{array}$ & & & & $0 / 5$ & $0 / 5$ & $0 / 3$ & & \\
\hline $\begin{array}{l}\text { Leísmo de entidad contable } \\
\text { plural }\end{array}$ & & & $0 / 4$ & $1 / 0$ & & $0 / 1$ & $0 / 3$ \\
\hline $\begin{array}{l}\text { Leísmo de entidad contable } \\
\text { abstracta singular }\end{array}$ & $1 / 1$ & & $1 / 5$ & $1 / 0$ & & $3 / 0$ & $2 / 0$ \\
\hline Leísmo de referente neutro & & $0 / 10$ & $0 / 2$ & $0 / 7$ & $0 / 3$ & & $0 / 1$ & $0 / 4$ \\
\hline
\end{tabular}

FiguRA 3.-Leísmo/uso etimológico con referente cosa o entidad en Toledo en los ss. XV-XVIII

Por tanto, queda probado el triunfo de un sistema referencial, al menos en la ciudad de Toledo, que opone en singular los referentes contables (42 y 43) a los no contables (44 y 45):

(42) y para esto suplico a vuestra señoría sea serbido darme licencia para que pueda poner mi banco de herrador en la puerta del Cambrón, en la parte que Cáceres, herrador, le tubo munchos años (TOLEDOC 226, Toledo, 1599); (43) Domínico Theotocópuli, vecino d'esta ciudad, digo que yo é echo un retablo para la capilla de Isabel de Oballe, el cual é echo por orden de vuestra señoría, y le tengo acabado (TOLEDOC 302, Toledo, 1613).

(44) por ser como son tan justas y probechosas para remediar la desorden qu'el labrar y curtir la dicha colambre y para remediar los excesivos precios en que está el dicho calçado, y de cada día se sube más, y esto por la malicia de los que lo venden (CODEA 269, Toledo 1551); (45) Grabiel de la Puerta y Francisco de la Fuente, cozineros, por nós y por los demás cozineros d'esta ciudad, decimos que en ella munchas personas que no son oficiales de cozina hazen manjar blanco sin saberlo hazer (CODEA 2085, Toledo 1613).

Todo esto no obstante, no faltan en Toledo en pleno s. XVII usos etimológicos, pues para entidades contables como cajón y pilar se emplea alguna vez lo: (46) "Iten es condición que en el paxar de dichas casas se ha de desbaratar 
un caxón de tres tapias de largo y cuatro de alto y bolverlo azer de nuevo aciendo su boquerón para echar la paxa (TOLEDOC 287 Toledo)"; (47) “[...] allamos tiene un pilar medianero [...] volviendolo a fabricar de nuevo" (Archivo Municipal de Toledo, Archivo Secreto-04-02-101, Toledo 1661).

Para referentes neutros, documentados en numerosos casos de los corpus estudiados, solamente encontramos ejemplos de $l o$, entre los que mostramos el siguiente de la ciudad de Toledo:

(48) Es condición que toda esta obra de carpintería es de manifatura, por que la madera y clabaçón la ha de dar el combento en la parte más cerca para que la metan, que será en la plaçuela de los Padillas, y lo ha de acer dando la costa (TOLEDOC 291, Toledo, 1663).

Por último, de manera excepcional, observamos un uso leísta para referente femenino incontable, peste, que posiblemente fue influido por la marca morfológica $-e$ del sustantivo (cf. el/la chinche en el castellano general y el superficie en TOLEDOC 45 1r 21) ${ }^{24}$.

(49) digo que juro a Dios y a esta cruz + y a los santos cuatro Evangelios que ninguno de todos cuantos allí están tiene peste, ni le ha tenido ni señal ni sospecha de ella (CODEA 2082, Toledo, 1599).

En cuanto al laísmo, se encuentra para persona femenina singular $(50,51$, 52 y 53) y, en un caso, plural $(54)^{25}$ :

(50) Doña Clara de la Fuente, [...] Suplica a vuestra gracia la haga merced de mandar dar licencia para que con su carro embíe por leña en cantidad de diez carros (TOLEDOC 232, h.1607); (51) el presente de gallinas y perdices que los vasallos de su señora de la dicha señora abadesa la'stán obligados a pagar en cada un año (TOLEDOC 376, Azután, 1646); (52) Los días pasados doña Teresa de las Roelas me escribió cómo se le quitara una celda que era de doña Acacia de Aragón, motibando se le hacía injusticia en quitarla lo que era suyo (TOLEDOC 292 Toledo, 1672); (53) y a Pepita cuando Vmd. la bese la dará Vmd. dos vesos más, uno por mí, y otro por don Juan (Toledo, 1700, Alfonso Vargas y Montes ${ }^{26}$ ).

\footnotetext{
${ }^{24}$ Agradecemos a Inés Fernández-Ordóñez la sugerencia de que le pueda ser ultracorrección para evitar la frecuente fusión entre la - $a$ del pronombre y el auxilar (l'ha).

${ }^{25}$ Cierta extensión del laísmo en épocas posteriores parece haber habido en Toledo, y no necesariamente entre los más incultos, a juzgar por casos como este: "Toledo a 19-IV-1937. Mi queridísimo hijo: Como va por edades hoy te toca a ti que te mande una postal y a la fea de Mogena ya la irá otro día, eso que no me escribe siempre que lo hace tu madre, pero si se vuelve a repetir ya no os mandaré postales ni nada. No dejes todos los días de estudiar francés [...]". Tampoco es descartable del todo considerar un referente genérico en la irá, en el sentido de 'le tocará a ella' ("Documentos interesantes", n. ${ }^{\circ}$ 50, en <https:/www.toledo.es/toledo-siempre/documentos-interesantes/>).

${ }^{26}$ Se ha de notar el alto nivel sociolingüístico del emisor, lo que se deduce claramente de otros segmentos de la carta: “¿para qué se han de gastar entre los dos circunloquios?”.
} 
(54) Leonor, portuguesa, digo que la víspera y día del Santíssimo Sacramento yo saqué una dança de portuguesas para servir a Nuestro Señor y alegrar a esta ciudad. Y demás de mi persona puse mucho cuidado en vuscar las compañeras que me ayudaren, prometiéndolas paga y remuneración (TOLEDOC 303, Toledo, 1600).

De todas formas, también es posible ver en Toledo ejemplos de uso etimológico del dativo femenino, tanto en singular como en plural, en el s. XVI (55) e incluso avanzado el XVII (56), lo que apunta a una extensión menor del laísmo que la que se aprecia en la ciudad de Madrid (v.i. 7.3):

(55) recivimos por monja y para monja professa de coro del dicho monesterio a la dicha doña María de Mendoza, la cual nos obligamos de le dar el ávito de orden (San Clemente, Toledo, 1574).

(56) Los días pasados doña Teresa de las Roelas me escribió cómo se le quitara una celda [...]; declarando a cuantas monjas les está concedida la celda, aposento, alacena o almario que tienen para su uso (TOLEDOC 292, Toledo, 1672).

\subsection{Madrid}

En la actual provincia de Madrid, como se espera en un espacio situado más al norte, durante los ss. XVI y XVII domina el sistema leísta referencial y está generalizado para persona masculina singular (57) y plural (58). También aparece el leísmo para nombre de animal singular (59):

(57) recivió [...] a Isidro de Cárdena [...] para destetarle y acavarle de criar (CODEA 1507, Madrid, 1633).

(58) Francisco de Salaçar, alcaide de la cárzel real d'esta villa, digo que en ella ay presos ocho hombres que lo fueron con el pretesto de que bayan a servir a su magestad, los cuales están padeziendo mucha nezesidad y ambre por ser pobres de toda solenidad y no tener quien les asista (CODEA 1754, Alcalá de Henares, 1677).

(59) [...] el rocín (...) y el dicho Francisco Sánchez le recibió (Archivo Municipal de El Escorial, El Escorial, 1587).

La documentación madrileña proporciona, pues, abundantes testimonios de leísmo de persona masculino singular, con 17 casos en la primera mitad del s. XVI y 47 en la segunda (Figura 4). Esto no quiere decir que no tenga presencia el uso etimológico, pues aparece 7 veces $l o$ frente a 30 muestras de $l e$ en la primera mitad del s. XVII. El leísmo de persona plural proporciona solo 3 ejemplos, todos ellos en el s. XVII, lo que apunta a una cronología relativamente más tardía que la del singular. Para referente animal singular domina ampliamente el leísmo, con 27 ejemplos de le por ninguno de lo en la segunda mitad del s. XVI, mientras que en la primera de esa centuria y en la primera del XVII aparecen, respectivamente, 1 y 2 . 


\begin{tabular}{|l|c|c|c|c|c|c|}
\hline \multicolumn{1}{|c|}{ Tipo de alteración } & \multicolumn{2}{|c|}{ s. XV } & \multicolumn{2}{c|}{ s. XVI } & \multicolumn{2}{c|}{ s. XVII } \\
\hline Leísmo de persona masculino singular & & & $17 / 0$ & $47 / 3$ & $30 / 7$ & $13 / 0$ \\
\hline Leísmo de persona masculino plural & $0 / 2$ & & $0 / 3$ & $0 / 2$ & $1 / 0$ & $3 / 0$ \\
\hline Leísmo animal masculino singular & & & $1 / 0$ & $27 / 0$ & & $2 / 0$ \\
\hline Leísmo animal masculino plural & & & & $0 / 1$ & & \\
\hline
\end{tabular}

FIGURA 4.- Leísmo/uso etimológico con referente animado en Madrid en los ss. XV-XVII

Para entidad contable abstracta se encuentra $l e$, como en el sustantivo salario (60). El sustantivo contable se referencia con el pronombre le (61) y el incontable, con lo (62), como en Toledo y en las demás zonas de sistema referencial.

(60) Contreras, y el salario que por razón de lo susodicho vós y ellos oviéredes de ver venidos que seáis os le mandaremos pagar (CODEA 992, Madrid, 1596).

(61) dichos vienes se allaron en el dicho cofre y se bolvieron a meter dentro d'él y cerrarle (CODEA 1511, Madrid, 1653).

(62) [...] el azeite que Mena bende [...] se sufre benderlo, [...] calentarlo en una sartén [...] lo viesen calentallo (Archivo Municipal de El Escorial, El Escorial, 1587).

En el corpus examinado, cuando el referente es entidad contable masculina singular está generalizado el leísmo; especialmente significativos son los 10 casos de la segunda mitad del s. XVI (Figura 5); por el contrario, no hay ejemplos de lo para este referente en todo el ámbito temporal abarcado. Por su parte no se documenta más que un caso de leísmo plural para cosa en la segunda mitad del s. XVII. Manifestación del sistema referencial es que con entidad incontable masculina singular (vino, trigo) aparezcan 4 y 2 casos de lo en la primera y segunda mitad del s. XVI respectivamente, y ninguno de $l e$. En cambio, con entidad contable abstracta (pleito), lo más relevante es la documentación de 13 casos de le frente a 2 etimológicos en la segunda mitad del s. XVI.

\begin{tabular}{|l|c|c|c|c|}
\hline \multicolumn{1}{|c|}{ Tipo de alteración } & \multicolumn{2}{|c|}{ s. XVI } & \multicolumn{2}{c|}{ s. XVII } \\
\hline Leísmo de entidad contable masculino singular & $1 / 0$ & $10 / 0$ & $2 / 0$ & $8 / 0$ \\
\hline Leísmo de entidad incontable masculino singular & $0 / 4$ & $0 / 3$ & $0 / 2$ & $1 / 7$ \\
\hline Leísmo de entidad contable plural & $0 / 17$ & $0 / 12$ & & \\
\hline Leísmo de entidad contable abstracta singular & & $13 / 2$ & & $1 / 0$ \\
\hline
\end{tabular}

FIGURA 5.- - Leísmo/uso etimológico con referente entidad en Madrid en los ss. XVI-XVII 
Por lo tanto, en las provincias de Madrid y Toledo el uso de lo (63) es general para el referente neutro ${ }^{27}$, mientras que el leísmo se extiende para entidad contable abstracta del tipo pleito:

(63) que en tal casso el pleito principal y pretensión que vuestra señoría tiene aora a toda la hazienda de Isavel de Ovalle quedasse en su fuerça para que vuestra señoría pudiesse continuarle y acavarle (TOLEDOC 201, Madrid, 1588).

Otro fenómeno acreditado en los documentos de Madrid es el laísmo, tanto para referente femenino singular como plural. Está generalizado ya en el s. XVII en la documentación de la capital: (64) "Aunque esta testigo bea la dicha muger no la conocerá, porque, como lleba declarado, no la bio la cara con el manto más de la punta de la nariz" (CODEA 1507, Madrid 1633); (65) “doña Isavel del Corral y a doña Lorenza del Corral, donzellas, hijas del dicho Juan Baptista del Corral, a cada una, una sortija de oro con un diamante que tengo en las manos, y las pido me encomienden a Dios" (CODEA 1512, Madrid 1661).

\section{FACTORES EXPLICATIVOS DE LA VARIACIÓN}

\subsection{Factor cronológico}

Es en el masculino plural donde mejor se aprecia la evolución de los usos leístas. Frente al leísmo de referente animado masculino singular, bien documentado desde la segunda mitad del s. XVI, el leísmo plural se da en Toledo solo con cierta intensidad en la segunda mitad del s. XVII, período en que la forma les domina sobre los en proporción 4 a 0 , mientras que en la primera contamos un solo caso de cada una. Por lo tanto, los datos, aunque escasos, indican que el cambio se produce más tarde en el plural que en el singular, según se muestra en la figura 6.

\begin{tabular}{|c|c|c|c|c|c|c|}
\hline Tipo de alteración & \multicolumn{2}{|c|}{ s. XV } & \multicolumn{2}{|c|}{ s. XVI } & \multicolumn{2}{|c|}{ s. XVII } \\
\hline $\begin{array}{l}\text { Leísmo de referente animado masculino } \\
\text { singular }\end{array}$ & & $3 / 2$ & $2 / 0$ & $8 / 0$ & $9 / 0$ & $4 / 0$ \\
\hline Leísmo de referente animado masculino plural & & $0 / 1$ & & $0 / 2$ & $1 / 1$ & $4 / 0$ \\
\hline
\end{tabular}

FIGURA 6.-Leísmo/uso etimológico con referente animado singular y plural en Toledo en los ss. XV-XVII

${ }^{27}$ No obstante, encontramos un caso marginal de leísmo con un antecedente neutro, probable asimilación con la secuencia habitual se le: "Suplica a vuestra merced le dé a criar [al niño], porque es muy probe, que Dios se le pagará, y de buena parte" (CODEA 1721 ARCM, [Madrid] 1600). 
La misma cronología para el leísmo plural se encuentra en la provincia de Madrid, donde no hay ejemplos significativos hasta la segunda mitad del s. XVII, lo que apunta a una difusión tardía. Por otra parte, es notorio el contraste con la extensión temprana en el s. XVI en el singular, con 18 casos en la primera mitad y 74 en la segunda (Figura 7).

\begin{tabular}{|l|c|c|c|c|c|c|}
\hline \multicolumn{1}{|c|}{ Tipo de alteración } & \multicolumn{2}{|c|}{ s. XV } & \multicolumn{2}{|c|}{ s. XVI } & \multicolumn{2}{c|}{ s. XVII } \\
\hline $\begin{array}{l}\text { Leísmo de referente animado masculino } \\
\text { singular }\end{array}$ & & $0 / 1$ & $18 / 0$ & $74 / 3$ & $30 / 7$ & $15 / 0$ \\
\hline Leísmo de referente animado masculino plural & $0 / 2$ & & $0 / 3$ & $0 / 3$ & $1 / 0$ & $3 / 0$ \\
\hline
\end{tabular}

FIGURA 7.- - Leísmo/uso etimológico con referente animado singular y plural en Madrid en los ss. XV-XVII

\subsection{Factor sociolingüístico. Extensión del leísmo en los grupos sociales}

En el acercamiento metodológico a la variación del pronombre objeto, los estudios sugieren la posibilidad de que el leísmo apareciera como una forma socialmente marcada. Para demostrarlo, la dificultad radica en documentar el registro más bajo. La ampliación de la escritura en el s. XVI proporciona algunos testimonios en los ambientes débilmente alfabetizados de gran valor por su excepcionalidad. Las notas de abandono son una muestra de este nivel sociocultural. Precisamente, el contraste entre estas notas y la documentación de tipo notarial de la Inclusa madrileña revela claramente que el leísmo estaba generalizado en toda la escala social. En una nota de abandono (66) y en una escritura notarial de prohijamiento (67) se encuentra leísmo de persona masculino singular.

(66) Este niño no esta baptiçado. Bautízenle (CODEA 1535, Madrid, 1595). (67) [...] un niño que se llama Balentín d'Espinossa, que es de edad de siete años poco más o menos, que se crió en Pinto, y le recibo en presencia del escribano y testigos (CODEA 1506 [Madrid] 1629).

En la siguiente tabla (Figura 8) se pueden ver los casos registrados en los dos tipos textuales en los que se clasifican los fondos de la Inclusa. En ella se aprecia, dentro de la desigualdad de cifras, el empleo casi sin excepción de le con referente de persona masculino singular independientemente del nivel sociocultural de quienes escriben, pues estos se sitúan en los dos polos de la escala, escribanos de oficio, los redactores de los documentos administrativos de la Inclusa, y personas de baja extracción social, para casi todos los casos, según podemos suponer, en quienes escriben las notas. Por lo tanto, a falta de 
más datos, se concluye que el leísmo no funcionaba como un marcador sociolingüístico en Madrid en los ss. XVI y XVII.

\begin{tabular}{|l|c|c|}
\cline { 2 - 3 } \multicolumn{1}{c|}{} & s. XVI & s. XVII \\
\hline Notas de abandono & $8 / 0$ & $3 / 1$ \\
\hline Otra documentación ARCM (Inclusa) & $9 / 1$ & $20 / 0$ \\
\hline
\end{tabular}

FIGURA 8.-Leísmo/uso etimológico con referente persona masculino singular en Madrid en diferentes escalas sociales (Notas de abandono y documentación notarial de la Inclusa)

\subsection{Factor geográfico}

Como ensayo provisional, y con vistas al establecimiento de diferencias geográficas internas de la Comunidad de $\mathrm{Madrid}^{28}$, además de la propia ciudad, hemos seleccionado varios enclaves en las distintas áreas que la conforman, y entre las que pueden establecerse diferencias históricas marcadas por su vinculación a territorios dispares ${ }^{29}$. Provisionalmente, consideraremos El Escorial (Cuenca del Guadarrama) y Alcalá de Henares, Daganzo y Arganda del Rey (Comarca de Alcalá). La distribución de los municipios se muestra en el mapa de la página siguiente (Figura 9).

A modo de muestra, en el Escorial observamos un uso referencial generalizado, del que destaca la temprana documentación del laísmo. También hemos podido hallar numerosos casos en los que se referencian entidades animadas siempre con leísmo en singular y plural. Igualmente se encuentra la distinción de pronombre átono en el referente masculino singular incontable $\mathrm{y}$, avanzado el s. XVII, hace aparición el loísmo plural $^{30}$.

\footnotetext{
${ }^{28}$ A pesar de que Moreno et al. (1988: 109) encuestan 23 localidades madrileñas (Alcalá de Henares, Algete, Aranjuez, Arganda del Rey, Boadilla del Monte, Bustarviejo, Brunete, Chinchón, El Escorial, Hoyo de Manzanares, Loeches, Manzanares el Real, Morata de Tajuña, Navacerrada, Navalcarnero, Paredes de Buitrago, Talamanca, Titulcia, Torrejón de Ardoz, Pinto, Villamanrique de Tajo, Rascafría, San Martín de Valdeiglesias), concluyen que "Los mapas incluidos en el apéndice II mostrarán la imposibilidad de delimitar áreas en las que incidan con más fuerza los tres fenómenos en conjunto o consideradas separadamente".

${ }^{29}$ Así, se ha de notar que El Escorial se vincula inicialmente a Segovia, pero tras el inicio de la construcción del monasterio de San Lorenzo la relación principal se establece con la ciudad de Madrid.

${ }^{30}$ Muestra de laísmo es "Requirió a Alonso Monedero de Fraça [...] con la dicha María Díez sobre los treinta e cuatro reales que le pide, el cual dixo que solamente la debe veinte e un reales y cuatro libras" (3382-1. El Escorial, 1588). Hay leísmo en singular en "[...] cuando algún perro parece que anda por el dicho sitio los peones e algunos oficiales le tiran muchas piedras y le dan mucha grita hasta que le matan (Archivo Municipal de El Escorial, 3380-1. El Escorial, 1534)", pero no en plural: "saquen los perros de la jurisdición o los tengan atados con apercibimiento que se mandarán matar" (3447-14. El Escorial, 1587). Frente a los casos de referente cosa en los
} 


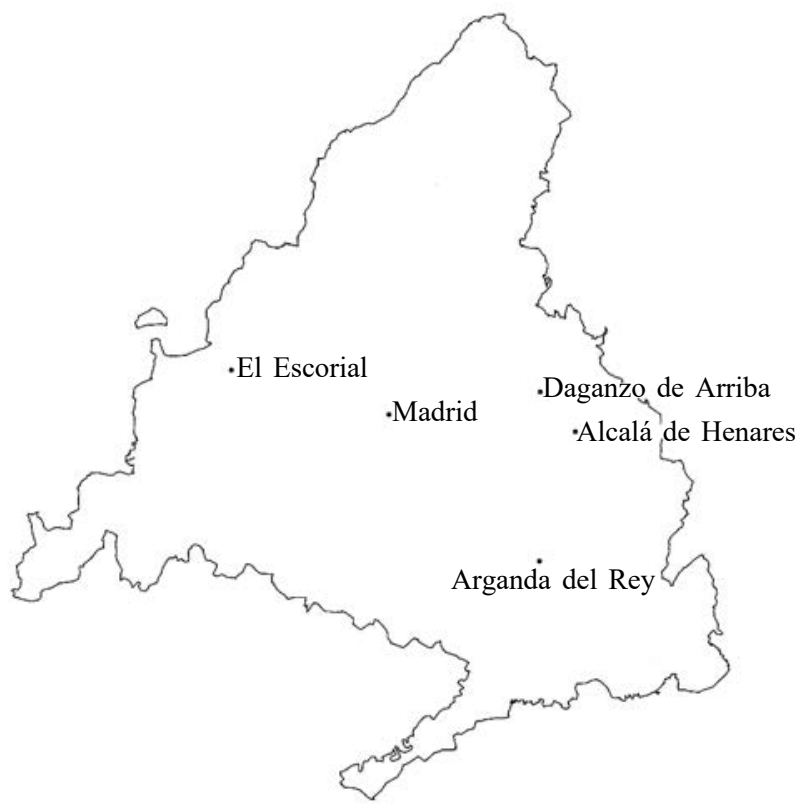

Figura 9.- Mapa de la Comunidad de Madrid con las localidades citadas

De Daganzo de Arriba conservamos una rica documentación de los ss. XVI y XVII, sobre todo de tipo judicial (Paredes García, 2010) ${ }^{31}$, la cual es proclive a referenciar en dativo la persona, masculina y femenina. Esta documentación muestra un sistema pronominal con apariciones de laísmo en el s. XVI, aunque minoritario respecto al uso etimológico (3 frente a 11). Por su parte, en Arganda del Rey (Vázquez Balonga, 2014) se aprecia en los ss. XVI y XVII un sistema referencial con preferencia por el leísmo en persona singular y objeto contable, que se combina con el laísmo. Sin embargo, hay a finales del s. XVI y en todo el XVII ejemplos de usos etimológicos asentados.

En Madrid capital se encuentra un sistema referencial con extensión del leísmo y laísmo ${ }^{32}$. En cuanto al laísmo singular, examinamos los casos de la

que se los es frecuente, no hemos encontrado ejemplos para persona. No obstante, los incluimos aquí por el posible contraste con se los en la lengua de uso: “[...] condenó a la satisfación d'ello a los jurados que avían sido d'esta villa desde el año de noventa y seis asta este presente [...] por escusar no se les culpase y molestase" (Archivo Municipal de El Escorial, El Escorial, 1699).

${ }^{31}$ Esta edición fue llevada a cabo dentro del Grupo de Investigación de Textos para la Historia del Español (GITHE) y se ha incluido en el corpus CODEA, lo mismo que la de Arganda.

${ }^{32} \mathrm{La}$ falta de documentación del laísmo no permite conclusiones sobre diferencias geográficas internas en la provincia de Toledo. Con todo, el laísmo tiene presencia en singular y en plural en la primera mitad del s. XVII (v. s. 5.1). 
ciudad de Madrid (fondo Inclusa) y las localidades de Daganzo, Arganda del Rey y El Escorial (Figura 10). El laísmo permite apuntar una diferencia diatópica dentro de la región de Madrid, ya que, pese a la dimensión de la muestra, se podría indicar que este fenómeno tiene una difusión más temprana e intensa en la capital que en las otras tres localidades, con 6 casos de laísmo frente a 4 de le en la segunda mitad del s. XVI, y 11 usos laístas en la primera del XVII frente a ninguno de le. Podría ser relevante que en Arganda del Rey, al sureste de la capital, todavía en la segunda mitad del s. XVII domine el uso etimológico de le para objeto indirecto femenino singular, con 6 empleos de le por 5 de $l a$.

\begin{tabular}{|l|c|c|}
\cline { 2 - 3 } \multicolumn{1}{c|}{} & s. XVI & s. XVII \\
\hline Madrid (Fondo de la Inclusa) & $6 / 4$ & $11 / 0$ \\
\hline El Escorial & $1 / 0$ & $1 / 0$ \\
\hline Daganzo & $3 / 11$ & $1 / 0$ \\
\hline Arganda del Rey & $0 / 1$ & $5 / 6$ \\
\hline
\end{tabular}

FigURA 10.-Laísmo / uso etimológico singular en la Comunidad de Madrid

8. LA CONTINUIDAD DEL SISTEMA LEÍSTA Y SU EXTENSIÓN A ZONAS DE USO ETIMOLÓGICO (SIGLO XVIII)

El leísmo tiene un amplio arraigo en Madrid y Toledo, y muestra continuidad a lo largo del tiempo. En las cartas toledanas del s. XVIII hay casos de leísmo para entidad contable masculina singular, tanto propiamente contable (68 y 69) como contable abstracta (70). Para los sustantivos incontables masculinos singulares permanece el pronombre $l o(71 \mathrm{y} 72)$. En cambio, no está generalizado el leísmo para el referente animado masculino plural, ni en persona (73, 74 y 75) ni animal (76). Tampoco hay leísmo en nuestro corpus para plural (77). Por último, hay que destacar la extensión del laísmo tanto en singular (78) como en plural (79):

(68) A vuestra señoría Ilustrísima suplico se sirba desde luego teniéndolo todo así de presente mandar a dicha noble antigua cofradía no ponga el caxón en aquel sitio, y que habiéndosele puesto, le haga quitar y mudar a otro sitio en que no se cause tanto perxuicio (Toledo, 11 de abril de 1766, 29, <http://www.ayto-toledo.org/archivo/curiosos/curiosos.asp >); (69) [...] acordó se conteste a dicha carta dando gracias al autor de dicho libro [...] y este se pase a los señores agentes generales para que le vean y reconozcan (TOLEDOC 100b, 1792). 
(70) El conducto que sale a la calle es de las aguas llobidizas, y este no se le puede quitar su curso por donde siempre le ha tenido (TOLEDOC 45, Toledo, 1765).

(71) el ganado [...] lo custodia (TOLEDOC 74, Toledo 1781); (72) carbón de brezo [...] con las caballerías que lo conduzcan (TOLEDOC 81, San Pablo de Los Montes, 1781).

(73) Don Manuel del Conde [...] dize que se halla con sus padres muy ancianos y con repetidas instanzias para que pase a verlos (TOLEDOC 37, [Toledo], 1765); (74) [...] 20 sujetos con motivo de destinarlos al hospicio (TOLEDOC 77, La Puebla de Montalbán, 1781); (75) y dos hermanos pequeños, sin poder por su pobreza los parientes socorrerlos ni educarlos; [...] su hermana mal inclinada y dos pequeños se los introdujera con decreto judicial en la casa de caridad (TOLEDOC 81b, Retuerta del Bullaque, 1781). (76) y digo que bien notorio es los notables perjuicios que se están siguiendo en la abundancia de perros que llaman de presa o alanos y otros de esta especie [...] y les sean preciso para la guarda de sus casas no permitan salir por la calle, teniéndolos atados en sus casas o, en caso que alguna vez los saquen para algún camino, deve ser poniéndolos freno de forma que no puedan hacer daño (Archivo Municipal de Toledo, Toledo, 1779) ${ }^{33}$.

(77) $[. .$.$] y para ello es necesario treinta y ocho rollones, y para que los pue-$ da sacar y cortar [...] (TOLEDOC 49, [Las Ventas con Peña Aguilera], 1765). (78) Teresa Romero [...] suplica a Vuestra Señoría que para ellos se sirba dispensarla la limosna que su de su agrado (TOLEDOC 38, Toledo, 1765).

(79) digo tengo precisión a imbiar dichas cabras a los montes propios de Vuestra Señoría a efecto de echarlas el macho (TOLEDOC 57, Toledo, 1765).

La continuidad del sistema referencial queda asegurada por casos de referente contable como los ejemplos $(68,69$ y 70), mientras que con incontable se selecciona lo, para los sustantivos ganado y carbón.

También se observa la extensión del loísmo plural con el verbo poner en "poniéndolos freno" (76). Sin embargo, lo general parece seguir siendo en el s. XVIII la adopción de los para los objetos plurales, como se puede observar en los ejemplos citados $\left(73,74,75,76\right.$ y 77), por su naturaleza casi siempre contable ${ }^{34}$.

En la localidad de El Carpio de Tajo, en el centro-oeste de la provincia, un mismo documento de finales del s. XVIII contiene un posible caso de leísmo de cosa plural: (78) "[...] el propio que llevó el despacho les ha costado ya setenta y dos reales. Éstos se le pudo ahorrar, que no faltaría ocasión y persona de sa-

33 "Documentos interesantes", 33, <http://www.ayto-toledo.org/archivo/curiosos/curiosos.asp>.

${ }^{34}$ Se ha de notar que, aunque la localidad de Retuerta del Bullaque pertenece hoy a la provincia de Ciudad Real, históricamente se integra en la comarca de Los Montes, término y jurisdicción del ayuntamiento de Toledo. Ello explica que se adscriba a un sistema leísta para el singular en este mismo documento, "[...] el hermano mayor [...] y la justicia le remite al señor juez (ib.); fiando en los favores que a vuestra merced devo me atrevo a cansarle" (ib.) Del mismo modo, en Los Navalucillos, cerca de la misma comarca de los Montes, pero ya en la actual provincia de Toledo, "su hermano [...] apremiándole para ello" (TOLEDOC 85, 1781). 
tisfacción a quien se les [= los reales] pudo encargar" (TOLEDOC 91, El Carpio de Tajo, 27 de junio de 1781).

Identificamos, pues, un sistema referencial en la provincia de Toledo en el s. XVIII, heredero del que se ha formado en las dos centurias anteriores. Se puede encontrar una preferencia del hablante por el leísmo en sustantivos masculinos contables en singular, mientras que se emplea $l o$ en el caso de los incontables. Es notorio también el aparente asentamiento del laísmo tanto singular como plural, en contraste con los ejemplos aportados de los ss. XVI y XVII.

A su vez, en la Comunidad de Madrid en el s. XVIII parece generalizado el leísmo no solamente en persona singular (79 y 80), sino también en plural (81 y 82), junto al uso de los (83). Igualmente se constata la extensión del laísmo singular (84 y 85); aunque no hay datos del plural. De manera no sistemática aparece de nuevo el loísmo plural. Frente a esta estabilización del sistema leísta, permanece la distinción ante un referente incontable, como en el sustantivo plomo (86). En la localidad de El Escorial se registra el empleo de les para dativo junto al loísmo plural $(87)^{35}$ :

(79) [...] este niño [...] suplican a los señores le bauticen (ARCM, Madrid, 1715); (80) Andión [...] que se le echaría del sitio (Archivo de El Escorial, El Escorial, 1773); (81) [...] y a los dichos Francisco Rodrigo y Gabriel Barbero les absuelbo y doy por libres (Archivo Municipal de El Escorial, El Escorial, 1703); (82) Juan Rubio y Josep de Marcos Serrano [...] despache dos guardas en busca de cada uno, para que en caso de hallarles, les condujesen a esta villa [...] se sirva de mandar se les ponga presos (Archivo de El Escorial, El Escorial, 1770) ${ }^{36}$; (83) [Pedro Romero y Josep Vidal] [...] tubieron precisión de acudir al fiel que pasó para que los reciviese (Archivo $\mathrm{Mu}-$ nicipal de El Escorial, El Escorial, 1763).

(84) Teresa Sáez (...) dándola una de las citadas prebendas (ARCM, Madrid, 1778); (85) [...] una vaca [....] la pegué un rejonazo bien puesto (Archivo Municipal de El Escorial, El Escorial, 1769).

(86) El plomo lo recogió de lo que sobró (Archivo de El Escorial, El Escorial, 1770).

(87) [Pedro Romero y Josep Vidal] y por la mesonera que se dice mujer de Lorán no se los quiso recibir, y porque insistían en que les diese posada, los habló muy mal (Archivo Municipal de El Escorial, El Escorial, 1763) ${ }^{37}$.

\footnotetext{
${ }^{35}$ En la documentación estudiada de El Escorial del s. XVIII el loísmo tiene manifestación plena en plural, mientras que para el singular no hay ningún caso de lo para objeto indirecto: "Si la diferencia que dice que tubo con el huésped resultó de averle pedido algún precio escesivo [...] dijo que es cierto le pidió cuarenta reales [...] y al huésped le pareció mucho" (Archivo Municipal de El Escorial, El Escorial, 1763).

${ }^{36}$ Aunque el leísmo es menos evidente en la secuencia se les. Para los problemas de interpretación de la secuencia se le(s), v. Santiago Lacuesta (1975).

${ }^{37}$ Nótese la variación entre les diese posada / los habló muy mal. En el COSER se observa esta alternancia en Segovia en los plurales (v. s. nota 30).
} 
Los usos leístas han conocido una notable expansión en español moderno. Las formas no etimológicas se extienden fuera del ámbito geográfico del sistema referencial. Se trata de un leísmo ceñido a referentes animados, que algunos estudiosos han considerado como variante del sistema etimológico en cuanto que solo se diferencia de este por la aceptación del leísmo de persona singular. En regiones no leístas, como Aragón, encontramos en la segunda mitad del s. XVIII una notable presencia del leísmo personal, como se ve, entre otros casos, por una carta privada de 1774 escrita por un abogado de Zaragoza y conservada en el ARCM: (88) "el sacristán esta en la cárzel, y dize que ella le engañó; (...) y

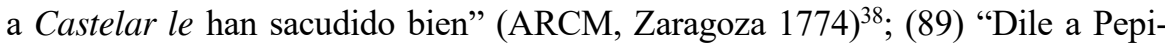
ta que no se desconsuele, que yo estoy absolutamente ciego y solo me ha quedado por el uso poder firmar como ves, pero confío en Dios, que no nos ha de dejar si le buscamos de veras" (CODEA 1895, Almendralejo, Badajoz, 1785) ${ }^{39}$.

Por lo tanto, se puede demostrar que el leísmo es un fenómeno constantemente sometido a variación a lo largo de la historia. Siendo este fenómeno de tanta complejidad, los factores sintácticos y semánticos de la selección del pronombre, los límites geográficos y la distribución sociolingüística y registral no se pueden considerar definitivas en un momento determinado.

\section{CONSIDERACIONES FINALES}

A la luz de las fuentes documentales examinadas, no resulta fácil identificar en los textos un sistema pronominal coherente que se correspondiera completamente con los usos de la lengua viva en un tiempo y espacio concretos, pues en los escritos intervienen factores internos de igualación de usos debido a su adscripción a un género textual. Por ello, no ha sido posible establecer subsistemas dentro de los usos referenciales que sí se han podido identificar con claridad para el s. XX.

Los documentos de los archivos toledanos parecen apuntar a una difusión tardía del sistema referencial en Toledo, pues en el s. XIV muestran formas etimológicas, mientras que en el XV, según nuestras fuentes, surgen los primeros testimonios de leísmo asociado a discontinuidad. Los usos innovadores acreditados en el s. XIII por códices regios como el de la Cuarta Parte de la General

\footnotetext{
${ }^{38}$ Los ejemplos de CORDE parecen indicar el uso transitivo de estos verbos (cf. la engaño y no *le engañó a ella). La extensión parece darse en verbos de un solo argumento; así engañar es siempre 'engañar a alguien', y este tipo sintáctico es proclive a referenciar el objeto con le incluso en zonas etimologicistas.

${ }^{39}$ En el siglo XVIII no son raros los ejemplos de leísmo en zonas distinguidoras: "el que suplica lo arrestó y puso en prisión, de cuyo justo prozedimiento lo que sacó fue que el governador le ubiese repreendido" (CODEA 1892, Badajoz, 1756).
} 
Estoria (Fernández-Ordóñez, 2001) no hallarían respaldo en la documentación medieval de Toledo, al menos de la ciudad ${ }^{40}$. Resulta relevante comprobar que los diplomas alfonsíes, y antes los de Fernando III, siguen mayoritariamente un sistema etimológico, lo que podría poner en duda la idea de que las innovaciones leístas triunfaron tempranamente en el espacio del castellano central. No está probado que los documentos representen de una manera directa los usos de la lengua hablada, pero ciertas reticencias que se observan en épocas posteriores a la generalización del leísmo parecen encajar con el predominio del sistema etimológico en Toledo durante la Edad Media.

La geografía del leísmo casaría, pues, con el carácter "secundario" del fenómeno en Toledo, y probablemente también en Madrid ${ }^{41}$, es decir, su posterioridad a la repoblación, pero también pone de relieve el peso que pudo tener en este proceso expansivo la organización del territorio del centro peninsular. La ausencia casi total del leísmo hoy en Ciudad Real, y su arraigo limitado en el sur y este de la actual provincia de Toledo, parece encajar con el peso que la ciudad de Toledo debió de tener como modelo lingüístico en un área de influencia extensa, que incluye Los Montes, tanto la parte toledana como de Ciudad Real. La necesidad continua de abastos de la ciudad de Toledo desde el s. $\mathrm{XV}$, probada por un gran número de testimonios documentales $\mathrm{s}^{42}$, crea una red socioeconómica sólida que pudo contribuir a extender en su amplia "tierra, montes y propios" el sistema referencial ${ }^{43}$.

\footnotetext{
${ }^{40}$ Resulta difícil probar la filiación geográfica de los códices alfonsíes, pues en ellos debieron de alternarse diferentes manos anónimas. Matute Martínez (2004) identifica un sistema referencial en el Libro conplido de los iudizios de las estrellas, cuyo manuscrito es un original del s. XIII probablemente elaborado en Toledo. En cuanto a los documentos de la cancillería, se ha señalado el predominio de escribanos procedentes de Segovia, Castilla oriental y Toledo (Fernández-Ordóñez, 2004: nota 67). Al parecer, todos se atendrían a unos usos etimológicos que podrían ser rasgo propio de este tipo textual. El recurso a modelos previos y la interiorización de los mismos pudieron ayudar al establecimiento de los usos etimológicos como característica lingüística de los diplomas regios.

${ }^{41}$ Se debe tener en cuenta la disparidad probatoria de los testimonios, pues si bien para Toledo contamos con numerosos documentos datados y localizados, para Madrid nos basamos sobre todo en el fuero de la villa.

${ }^{42}$ Las entradas continuas de mercancías, sobre todo de los territorios situados al sur de la capital del Tajo y de Los Montes, se prueban por las regulaciones como las de las Ordenanzas de 1400 (Tello Martín, 2006) y los libros de aranceles del XVI (Sánchez Sierra, 2013); la leña, la greda para los paños y hasta ranas se vendían en la ciudad (sobre los abastos, véase también Izquierdo Benito, 2002).

${ }^{43}$ Entendemos como factor importante en la configuración de los límites del leísmo esta influencia económica de la ciudad de Toledo y tal vez no tanto la extensión del arzobispado. En cualquier caso, parece que los territorios del sur y el este del arzobispado (Ciudad Real y el sector oriental de Toledo) tienen una presencia significativa de las órdenes militares: la de Santiago en Ciudad Real y la de Uclés en el sector oriental de Toledo. Además, varias poblaciones del este, centro y sur de Ciudad Real pertenecieron al concejo de Alcaraz (véase la relación en CODEA 1205, carta por la que Fernando III parte términos entre la Orden de Santiago y el concejo de Alcaraz).
} 
Sin embargo, el proceso relativamente tardío de expansión no se explica sin entender que las alteraciones pronominales no alcanzaron, ni alcanzan hoy, un grado de fijeza absoluto, sino que están en continua fluctuación, empezando por la idiolectal, y, por lo mismo, son susceptibles de influencias diversas. De ahí que la villa de Madrid, de notable importancia histórica ya desde el s. XV (Rábade Obradó, 2009), pudiera realimentar el leísmo toledano en los ss. XVI y XVII y aun después. La generalización en todos los ámbitos sociales del leísmo de base referencial es clave para entender la capacidad de "contagio" a quienes siguen acudiendo a la capital del reino en épocas sucesivas, incluso en el s. XX.

Gran interés para nuestro propósito, por su valor de "ensayo", tiene la localidad de El Escorial, pequeña villa medieval que conoció un importante crecimiento con la afluencia de un gran número de trabajadores que se instalan en ella para la construcción y luego mantenimiento del monasterio de Felipe II, a lo que se añade la población que va de paso para Madrid o por otros asuntos (suministros, caza, ganadería). Los documentos atestiguan la presencia de extranjeros de diversos países de Europa, así como personas de otros territorios peninsulares ${ }^{44}$, lo que apuntaría a una contienda entre usos lingüísticos, y en concreto, en lo que afecta a la selección del pronombre. Sin embargo, los textos muestran soluciones marcadamente innovadoras en los usos pronominales, con extensión incluso del loísmo plural (v. s. 7.3. los habló muy mal).

Para valorar la división territorial es imprescindible tener en cuenta las capas cronológicas en la selección del pronombre. Se ha señalado que en el área occidental de la Comunidad de Madrid habría menos leísmo en el plural (Fernández-Ordóñez, 1999: 1386), pero este fenómeno ya está atestiguado para persona en la villa de El Escorial, situada en el oeste, al menos desde 1699, con se les (se les culpase), y, lo que es más significativo, con les (1703, les absuelvo y doy por libres) (v. s. 7.3 y 8$)^{45}$. Si nos detenemos en los aspectos internos de la evolución de las innovaciones, los documentos muestran indicios de que tanto en Madrid como en Toledo el leísmo de persona plural y el laísmo singular se introducen en el sistema pronominal de manera tardía respecto al leísmo singular, ya que los primeros datos aparecen en la transición entre los ss. XVI y XVII. En la segunda mitad del XVII les tiene mayor presencia en Madrid que en Toledo, lo que parece corroborarse por los usos observados en el s. XVIII en la provincia (58 teniéndolos atados [los perros], en 1779), y que coincide con los datos señalados en la sincronía actual.

${ }^{44}$ Hay referencias a franceses (El Escorial, 1688 y 1771), a portugueses (El Escorial, 1617 y 1723), el hallazgo de un hombre ahogado natural de Béjar (Salamanca) (El Escorial, 1680), a un maestro cantero navarro (El Escorial, 1623), a un criado gallego (El Escorial, 1696), entre otros.

${ }^{45}$ En cualquier caso, para animal masculino plural parece predominar el uso etimológico de los, como se aprecia en un documento de El Escorial de 1696, en el que el referente es cerdos. 
Parece asimismo que el laísmo se desarrolla con más rapidez en Madrid, frente a localidades del sureste, seguramente por su relativo aislamiento y por tratarse de un ámbito rural con menos dinamismo en el cambio lingüístico. Con todo, este fenómeno llega a extenderse con fuerza en el s. XVII tanto en la provincia de Madrid como en la de Toledo, según muestran los documentos de finales de la centuria. En cuanto al factor sociolingüístico, se puede apreciar el asentamiento del leísmo de persona singular en las notas de abandono de la Inclusa de Madrid, escritas por manos inhábiles, lo que es prueba definitiva de la generalización social de este fenómeno.

Por lo tanto, los datos, aunque escasos, nos proporcionan huellas de una diferencia entre Madrid capital y su entorno, así como entre la región madrileña y la provincia de Toledo, pero también parece evidente su paralelismo en el uso del leísmo para referente animado (persona y animal) y para objeto de entidad contable, es decir, un sistema referencial. Pese a las semejanzas claras, tal vez quepa establecer una frontera lingüística entre las dos áreas, vistos otros indicios hallados en la documentación. Es el caso de la existencia del neutro de materia en la Comunidad de Madrid (lana blanco), atestiguado, al menos, en Arganda del Rey, Daganzo, Getafe y Loeches a finales del s. XVII (Gómez Seibane y Vázquez Balonga, 2014) y en la sierra de Madrid (Morala, 2015: 327), lo que contrasta con los documentos de esa época de la provincia de Toledo, en los que no hemos encontrado este rasgo ${ }^{46}$. Tuten (2010: 9) señala solo dos casos en los aranceles de 1480 editados por Izquierdo Benito (2002) (carne ... lo, fruta ... lo), pero es general lo con incontables femeninos en este texto. Por occidente pudo llegar más al sur, pues se ha documentado alguna vez en la parte toledana de La Jara (Paredes García, 1999: 1200-1201) y Los Montes de Toledo (Moreno Fernández, 1999: 223-224).

Con todo, la prioridad en este momento es ampliar el corpus documental para alcanzar una mayor precisión geográfica. Uno de los objetivos al respecto sería examinar si el sistema referencial se extendió en el pasado a toda la provincia de Toledo, pues Klein-Andreu (2000) ha señalado que hoy este sistema parece vigente en el centro y norte de Toledo, mientras que en el sur el leísmo se limita a los casos de animación. En el plano general del proceso histórico que afecta a los pronombres átonos de tercera persona, el contar con un corpus cada vez más amplio de documentos originales de ámbito local permitirá calibrar mejor la extensión geográfica y social de las innovaciones.

\footnotetext{
${ }^{46}$ Fernandez-Ordóñez (2006) encuentra casos de neutro de materia con adjetivos en Pulgar (centro-sur) y en el occidente de Toledo.
} 


\section{BIBLIOGRAFÍA}

ALDICAM = Pedro Sánchez-Prieto Borja (coord.) (2016-): Atlas Lingüístico Diacrónico e Interactivo de la Comunidad de Madrid, <http://aldicam.blogspot.com.es/>.

Almeida Cabrejas, Belén, Pedro Sánchez-Prieto Borja y Delfina Vázquez Balonga (2015): "El pronombre átono objeto en la documentación toledana y su lugar en la dialectología histórica", en José María García Martín (ed.), Actas del IX Congreso Internacional de Historia de la Lengua Española, Madrid/Frankfurt, Iberoamericana/Vervuert, I, pp. 585-600.

$A L P I=$ García Mouton, Pilar (coord.), Inés Fernández-Ordóñez, David Heap, Maria Pilar Perea, João Saramago, Xulio Sousa (2016): ALPI-CSIC [www.alpi.csic.es], edición digital de Tomás Navarro Tomás (dir.), Atlas Lingüístico de la Península Ibérica, Madrid, CSIC.

Bustos Gisbert, Eugenio y Ramón Santiago (2000): "Para un nuevo planteamiento de la llamada «norma madrileña» (siglos XVI y XVII)", María Teresa Echenique y Juan Pedro Sánchez Méndez (coord.), Actas del V Congreso Internacional de Historia de la lengua Española, Madrid, Arco/Libros.

CODEA = GITHE (Grupo de Investigación Textos para la Historia del Español): CODEA+ 2015 (Corpus de documentos españoles anteriores a 1800) [en línea] <http://www.corpuscodea.es/>.

CORDE $=$ Real Academia Española: Banco de datos (CORDE) [en línea]. Corpus diacrónico del español, <http://www.rae.es>.

COSER = Inés Fernández Ordóñez (dir.) (2005-): Corpus Oral y Sonoro del Español Rural, $<$ http://www.corpusrural.es/index.php>.

Echenique Elizondo, M. ${ }^{a}$ Teresa (1981): "El sistema referencial en español antiguo: leísmo, laísmo y loísmo", Revista de Filología Española, 61, 1-4, pp. 113-158.

Fernández-Ordóñez, Inés (1999): "Leísmo, laísmo y loísmo", en Ignacio Bosque y Violeta Demonte (eds.), Gramática Descriptiva de la Lengua Española, vol. I. Sintaxis básica de las clases de palabras, Madrid, Espasa, pp. 1317-1340.

Fernández-Ordóñez, Inés (2001): "Hacia una dialectología histórica. Reflexiones sobre la historia del leísmo, el laísmo y el loísmo", Boletín de la Real Academia Española, LXXXI, pp. 389-464.

Fernández-Ordóñez, Inés (2004): “Alfonso X el Sabio en la historia del español”, en Rafael Cano Aguilar (coord.), Historia de la lengua española, Barcelona, Ariel, pp. 381-422.

Fernández-Ordóñez, Inés (2006): "Del Cantábrico a Toledo: El neutro de materia hispánico en un contexto románico y tipológico", Revista de Historia de la Lengua Española, I, pp. 67-118.

Frago, Juan Antonio (1999): Historia del español de América, Madrid, Gredos.

Gómez Seibane, Sara y Delfina Vázquez Balonga (2014): “¿Más huellas del neutro de materia en los Siglos de Oro? Algunos testimonios de la región de Madrid", Revista de Filología Asturiana, 13 , pp. $53-70$.

González, Javier (1987): "Repoblación de Toledo", Estudios sobre Alfonso VI y la reconquista de Toledo. Actas del II Congreso Internacional de Estudios Mozárabes (Toledo, 20-26 mayo 1985), Toledo, Instituto de Estudios Visigótico-Mozárabes, pp. 99-113.

González Ollé, Fernando (1996): El habla toledana, modelo de la lengua española, Toledo, Diputación Provincial de Toledo.

Infantes, Víctor (1998): De las primeras letras. Cartillas españolas para enseñar a leer de los siglos XV y XVI. Preliminar y edición facsímil de 34 obras, Salamanca, Ediciones Universidad de Salamanca.

Izquierdo Benito, Ricardo (2002): Abastecimiento y alimentación en Toledo en el siglo XV, Cuenca, Universidad de Castilla-La Mancha.

Klein-Andreu, Flora (2000): Variación actual y evolución histórica. Los clíticos le/s, la/s, lo/s, Múnich, Lincom Europa.

Lapesa, Rafael, Galo Sánchez, Agustín Millares Carlo, Pedro Rico y José María Álvarez del Manzano (1994 [1932]): El Fuero de Madrid, edición facsímil, Madrid, Ayuntamiento de Madrid. 
Lapesa, Rafael (2000): "Sobre los orígenes y evolución del leísmo, laísmo y loísmo", en Rafael Lapesa, Estudios de morfosintaxis histórica del español, Madrid, Gredos, I, pp. 279-310.

López García, José Miguel (1998): El impacto de la corte en Castilla. Madrid y su territorio en la época moderna, Madrid, Siglo XXI.

Martín Aizpuru, Leyre (2015): "Acercamiento al sistema pronominal átono de tercera persona en documentos de cancillería alfonsí", en Juan P. Sánchez Méndez, Mariela de la Torre y Viorica Codita (eds.): Temas, problemas y métodos para la edición y el estudio de documentos hispánicos antiguos, Valencia, Tirant Humanidades, pp. 695-710.

Matute Martínez, Cristina (2004): Los sistemas pronominales en español antiguo. Problemas y métodos para una reconstrucción histórica, Madrid, Universidad Autónoma de Madrid.

Morala, José Ramón (2015): "Datos para la historia del neutro de materia en castellano", Revista de Filología Española, XCV, 2, pp. 307-337.

Moreno Fernández, Francisco, Manuel Amorós Gabaldón, Javier Bercial Sanz, Francisco Corrales Fernández y M. a de los Ángeles Rubio Haro (1988): “Anotaciones sobre el leísmo, el laísmo y el loísmo en la provincia de Madrid", Epos, IV, pp. 101-122.

Moreno Fernández, Francisco (1999): "Castilla la Nueva", en Manuel Alvar (dir.), Manual de dialectología española. El español de España, Barcelona, Ariel, pp. 213-232.

Paredes García, Florentino (1995): Estudio sociolingüístico del habla de La Jara, tesis doctoral, Alcalá de Henares, Universidad de Alcalá.

Paredes García, Florentino (1999): "Neutro de materia y otras discordancias de género en Toledo", en José Antonio Samper Padilla y Magnolia Troya Déniz (coords.), Actas del XI Congreso Internacional de la Asociación de Lingüística y Filología de la América Latina. Las Palmas de Gran Canaria, 22-27 de julio de 1996, Las Palmas de Gran Canaria, Servicio de Publicaciones de la Universidad de las Palmas, II, pp. 1197-1206.

Paredes García, Florentino (2015): "Nuevos datos sobre el uso y las funciones de los pronombres átonos de tercera persona en Madrid", en Ana Cestero Mancera, Isabel Molina Martos y Florentino Paredes García (eds.), Patrones sociolingüísticos de Madrid, Berna, Peter Lang, pp. $177-250$

Paredes García, Florentino (dir.), Rocío Díaz Moreno, Rocío Martínez Sánchez, Ruth Miguel Franco, María Simón Parra e Irene Vicente Miguel (2010): Textos para la Historia del Español, V. Archivo Municipal de Daganzo, Alcalá de Henares, Servicio de Publicaciones de la Universidad de Alcalá.

Rábade Obradó, M. ${ }^{a}$ Pilar (2009): "Escenario para una Corte real: Madrid en tiempos de Enrique IV", E-Spania, Revue interdisciplinaire d'études hispaniques médiévales et modernes, <https:/ /e-spania.revues.org/18883>.

Sánchez-Prieto Borja, Pedro (2015): "Los documentos de los Archivos de Toledo y la historia de la lengua española", en Juan Pedro Sánchez Méndez, Mariela de la Torre y Viorica Codita (eds.), Temas, problemas y métodos para la edición y el estudio de documentos hispánicos antiguos, Valencia, Tirant Humanidades, pp. 136-154.

Sánchez-Prieto Borja, Pedro y Ana Flores Ramírez (2005): Textos para la Historia del español, IV. Archivo Regional de la Comunidad de Madrid, Alcalá de Henares, Servicio de Publicaciones de la Universidad de Alcalá.

Sánchez Sierra, Diego (2014): Edición y comentario de dos libros de aranceles toledanos del s. $X V I$, trabajo de fin de grado, Alcalá de Henares, Universidad de Alcalá.

Santiago Lacuesta, Ramón (1975): "Impersonal se le(s), se la(s), se lo(s)", Boletín de la Real Academia Española, 55, pp. 83-107.

Tello Martín, Alicia (2006): Edición de las "Ordenanças antiguas de la muy noble cibdat de Toledo", trabajo de investigación tutelado, Alcalá de Henares, Universidad de Alcalá.

Torrens Álvarez, María Jesús (2002): Edición y estudio lingüístico del Fuero de Alcalá (Fuero Viejo), Alcalá de Henares, Fundación Colegio del Rey. 
Tuten, Donald (2003): Koineization in Medieval Spanish, Berlin/New York, Mouton de Gruyter.

Tuten, Donald (2010): "The decline of the count/non count distinction in Castilian", Romance Philology, 64, pp. 1-21.

Vázquez Balonga, Delfina (2014): Textos para la Historia del Español, VIII. Archivo Municipal de Arganda del Rey, Alcalá de Henares, Servicio de Publicaciones de la Universidad de Alcalá.

Fecha de recepción: 9 de junio de 2016

Fecha de aceptación: 22 de septiembre de 2016 